\title{
Efficacité des Composés Organiques Volatils fongiques (synthèse bibliographique)
}

\author{
Amine Kaddes ${ }^{(1)}$, Marie-Laure Fauconnier ${ }^{(2)}$, Khaled Sassi ${ }^{(4)}$, Chadi Berhal ${ }^{(1)}$, \\ Bouzid Nasraoui ${ }^{(3)}$, M. Haïssam Jijakli ${ }^{(1)}$ \\ (1) Université de Liège - Gembloux Agro-Bio Tech (GxABT). Laboratoire de Pathologie végétale intégrée et urbaine. Passage \\ des Déportés, 2. BE-5030 Gembloux (Belgique).E-mail : amine.kaddes@doct.uliege.be \\ (2) Université de Liège - Gembloux Agro-Bio Tech (GxABT). Laboratoire de Chimie des Molécules naturelles. Passage des \\ Déportés, 2. BE-5030 Gembloux (Belgique). \\ (3) Institut National Agronomique de Tunisie. Université de Carthage. LR/Bioagresseurs et Protection Intégrée en Agriculture \\ (LR14AGR02). Tunis (Tunisie). \\ (4) Institut National Agronomique de Tunisie. Université de Carthage. Département d'Agronomie et de Biotechnologie \\ végétale. Tunis (Tunisie).
}

Reçu 25 juillet 2017, accepté le 22 janvier 2019, accessible en ligne le 30 mars 2020.

Cet article est distribué suivant les termes et les conditions de la licence CC-BY (http://creativecommons.org/licenses/by/4.0/ deed.fr)

Introduction. L'utilisation excessive de fongicides chimiques continue à pousser la recherche vers des alternatives pour la protection des cultures qui soient respectueuses de l'environnement, mais aussi novatrices.

Littérature. Les champignons produisent divers mélanges de composés en phase gazeuse, appelés Composés Organiques Volatils (COVs). Ils sont capables de se diffuser dans le sol et dans l'atmosphère et d'inhiber les activités des pathogènes fongiques. Dans cette section, nous résumerons les connaissances récentes sur le potentiel inhibiteur des Composés Organiques Volatils contre les champignons pathogènes en mettant l'accent sur l'effet des COVs fongiques. Dans la pratique, nous y dévoilerons les premières recherches déchiffrant leur mode d'action et les éventuels effets phytotoxiques non spécifiques sur le microbiome environnemental ainsi que sur les plantes.

Conclusions. Cet article porte sur les nouvelles techniques utilisées par les chercheurs qui mettent l'accent sur la mycofumigation afin d'optimiser la formulation d'une nouvelle génération de biofongicides. Ainsi, se dessine un nouvel horizon en matière de lutte biologique contre les maladies des cultures.

Mots-clés. Fongicide, champignons pathogènes, mycofumigation, lutte biologique, terpénoïde, phytotoxicité.

\section{Efficacy of fungi Volatile Organic Compounds. A review}

Introduction. Excessive use of chemical fungicides continues to drive research towards environmentally friendly and innovative alternatives for crop protection.

Literature. Fungi produce various mixtures of compounds in the gas phase, called Volatile Organic Compounds (VOCs). They are able to diffuse into the soil and into the atmosphere and inhibit the activities of fungal pathogens. In this section, we will summarize recent knowledge on the inhibitory potential of Volatile Organic Compounds against pathogenic fungi with a focus on the effect of fungal VOCs. In practice, we will unveil initial research revealing their mode of action and any non-specific phytotoxic effects on the environmental microbiome and on plants.

Conclusions. This article discusses new techniques used by researchers that focus on mycofumigation to optimize the formulation of a new generation of biofungicides. Thus, a new horizon is emerging for biological control of crop diseases.

Keywords. Fungicides, pathogenic fungi, mycofumigation, biological control, terpenoid, phytotoxicity. 


\section{INTRODUCTION}

À l'échelle mondiale, $70 \%$ des maladies des plantes sont causées par des pathogènes fongiques (Fisher et al., 2012). Certes, le marché mondial des produits phytosanitaires est largement dominé par les produits de synthèse. Mais certains de ces composés posent différents problèmes environnementaux et de santé humaine, en particulier pour les agriculteurs qui les manipulent à haute concentration. Parmi ces fongicides chimiques, nous notons l'imazalil, le thiabendazole et le bromure de méthyle. Des efforts ont été accomplis pour découvrir et développer de nouvelles stratégies plus écologiques connues sous le nom de biofongicides, organismes vivants ou produits issus de ces organismes ayant la particularité de limiter ou de supprimer les ennemis des cultures (Thakore, 2006). Ceux-ci sont moins toxiques que leurs homologues chimiques. Cette découverte a permis à la fois de réduire l'utilisation excessive des fongicides chimiques en agriculture et de diminuer leur impact néfaste sur l'environnement et la santé humaine.

Parmi les méthodes alternatives récemment explorées, on note le recours à l'utilisation des Composés Organiques Volatils (COVs) qui pourraient jouer un rôle dans la lutte biologique contre les agents pathogènes des plantes. Ces COVs sont des molécules organiques caractérisées par un faible poids moléculaire $(<300 \mathrm{Da})$ et présentant une forte pression de vapeur $\left(\geq 0,01 \mathrm{kPa}\right.$ à $20^{\circ} \mathrm{C}$ ) (Dudareva et al., 2006). Grâce à leurs propriétés physiques, ces molécules, une fois libérées dans l'atmosphère par les parties aériennes ou dans le sol par les racines des plantes terrestres, peuvent traverser les membranes cellulaires végétales, jouant ainsi un rôle très important dans l'interaction des végétaux avec leur environnement. Ces substances gazeuses sont impliquées dans la nature pour créer des micro-environnements permettant aux plantes d'interagir continuellement avec d'autres organismes qui partagent leur environnement. Les COVs peuvent être produits par divers organes de la plante (feuilles, fleurs, fruits et racines) et être des médiateurs clés dans les interactions biotiques à la fois en surface et en soussol (Dudareva et al., 2006 ; Peñuelas et al., 2014).

Ces COVs jouent un rôle très important dans la vie de la plante. Bien qu'il soit généralement admis que les composés émis par les fleurs servent à attirer et à guider les pollinisateurs (Reinhard et al., 2004), de nombreux volatils floraux ont une activité antimicrobienne ou antiherbivore (De Moraes et al., 2001; Friedman et al., 2002 ; Hammer et al., 2003) et pourraient donc également protéger les parties reproductives des plantes contre les ennemis.

Plus intéressant encore, les COVs, émis par les racines des plantes, constituent également des mécanismes de défense pour le monde végétal. Des recherches faites par Kaddes et al. (2019) ont montré que les COVs des racines de l'orge influencent et inhibent le développement des champignons pathogènes de l'orge (Kaddes et al., 2019). En tout cas, à l'heure actuelle, nous savons que les plantes, par le biais du bouquet de ces volatiles, peuvent également se défendre contre les agents pathogènes en inhibant ou tuant les microorganismes concurrents.

Cette publication présente une étude bibliographique visant à examiner le potentiel antifongique de 33 espèces de champignons. Le texte comporte trois grandes parties : la première est consacrée à l'énumération des effets inhibiteurs des COVs, identifiés à partir de différentes espèces de champignons ayant un pouvoir antifongique ainsi que l'illustration de leurs modes d'action; la deuxième partie porte sur la mise au point de bonnes pratiques agricoles basées sur de nouvelles approches consécutives à l'utilisation des $\mathrm{COVs}$ fongiques et des pistes innovantes concernant la mycofumigation; la troisième partie analyse l'effet toxique des COVs fongiques.

Le tableau 1 résume le potentiel inhibiteur des composés organiques volatils émis par les différents champignons contre les champignons pathogènes fongiques.

\section{POTENTIEL DE L'UTILISATION DES COMPOSÉS ORGANIQUES VOLATILS DANS LA PROTECTION DES CULTURES CONTRE LES MALADIES FONGIQUES MAJEURES}

\subsection{Phénomène de la fongistase}

Dès 1953, Dobbs \& Hinson ont démontré l'existence d'un facteur fongistatique révélant l'occurrence répandue d'un constituant organique antifongique présent en profondeur dans le sol et dont l'origine était inconnue (Schüepp \& Frei, 1969). Cette étude a été suivie par celle de Watson \& Ford (1973) qui ont montré que l'inhibition de la germination des propagules fongiques et la croissance des hyphes fongiques sont basées sur deux théories. La première montre que la carence en nutriments est à l'origine de cette inhibition fongique. La deuxième théorie dévoile l'existence des microorganismes antagonistes présents dans le sol ayant un effet antifongique. La combinaison de ces deux théories offre ainsi une explication de la fongistase induite par les COVs. Dans les années 1970, grâce aux recherches menées par Lockwood (1977), la fongistase est devenue un « sujet brûlant » axé principalement sur la compréhension de son mécanisme et de sa relation avec la suppression des maladies fongiques des plantes transmises par le sol.

Depuis, de nombreuses études ont été menées sur les propriétés physiques et les caractéristiques 


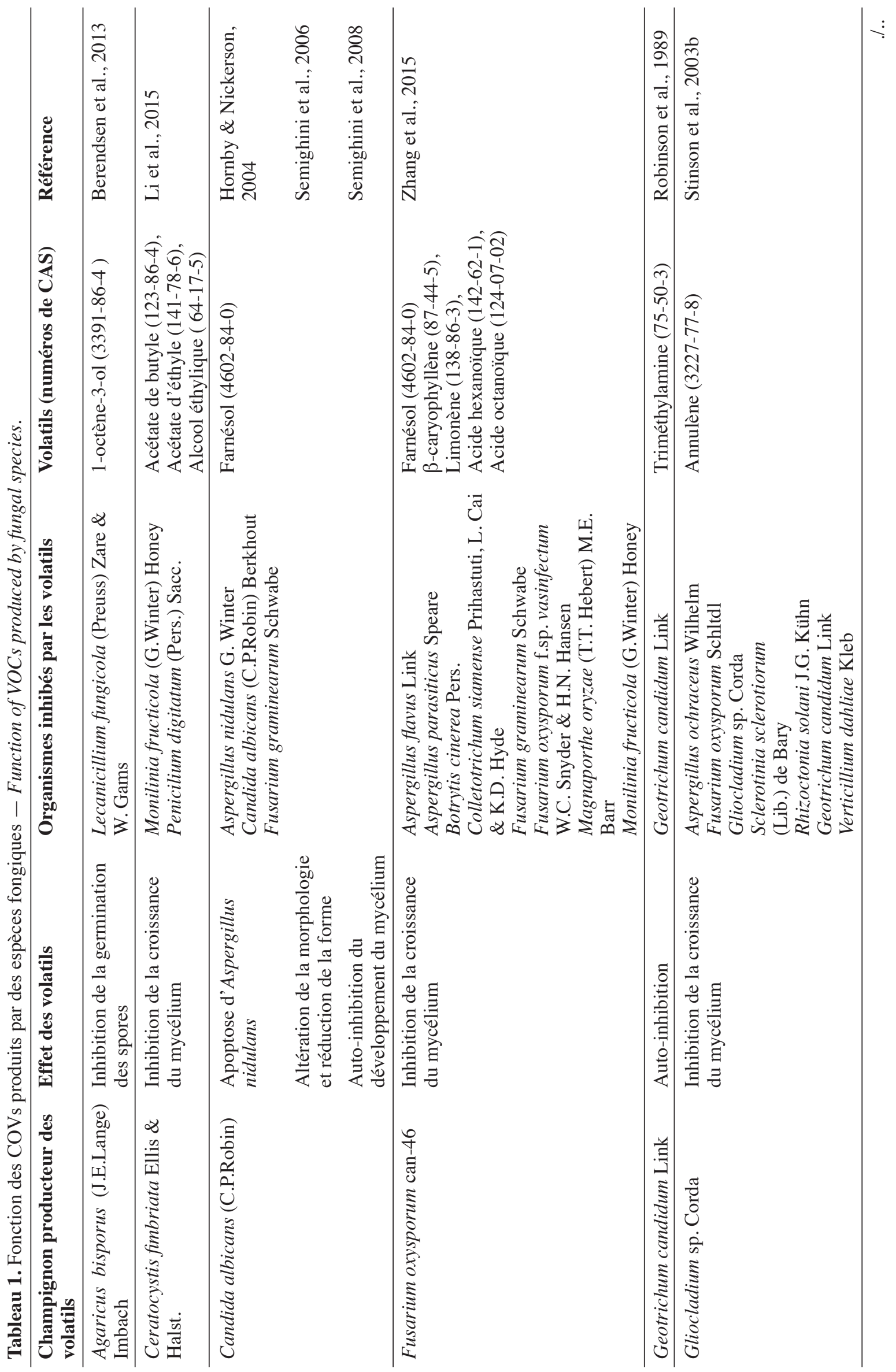




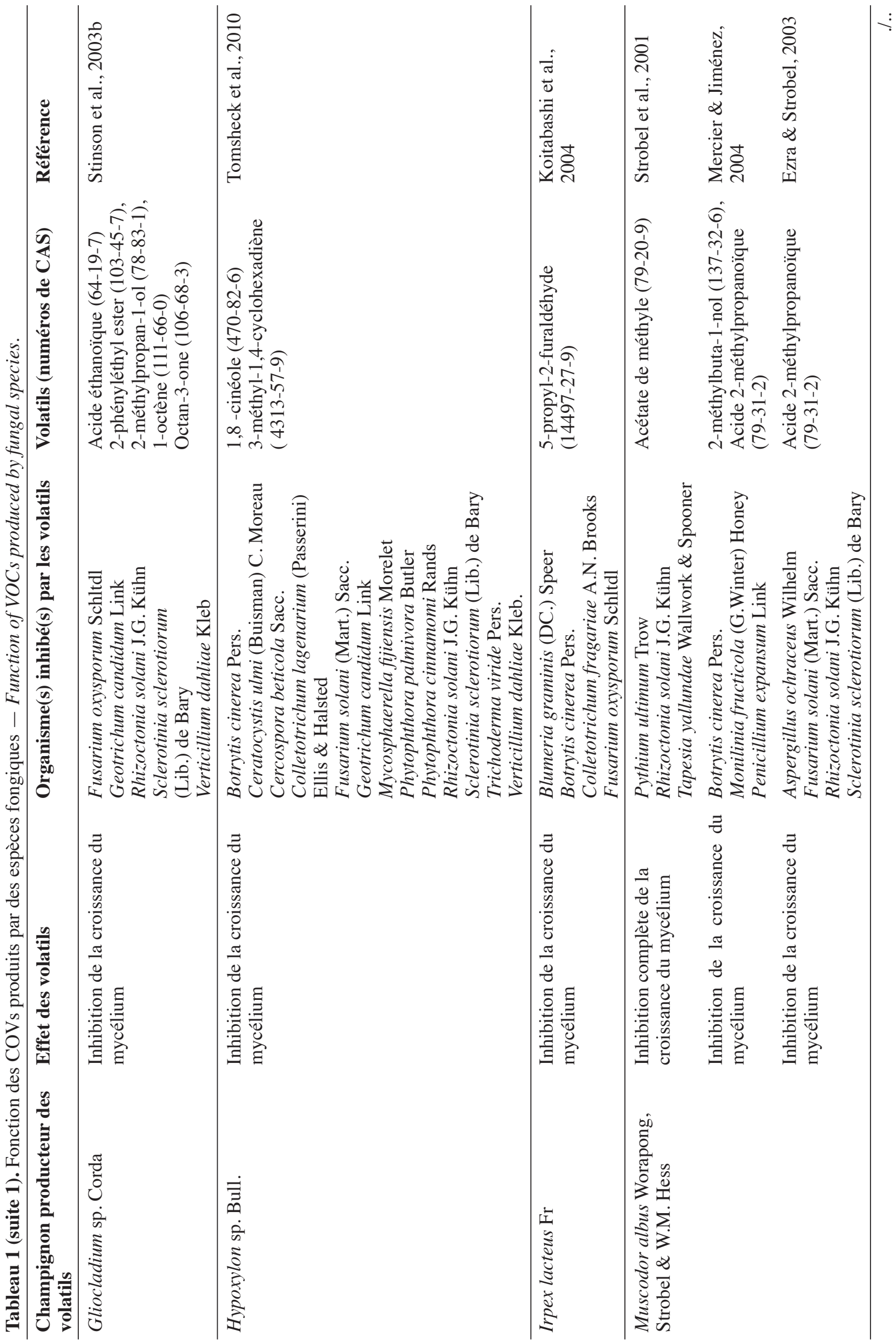




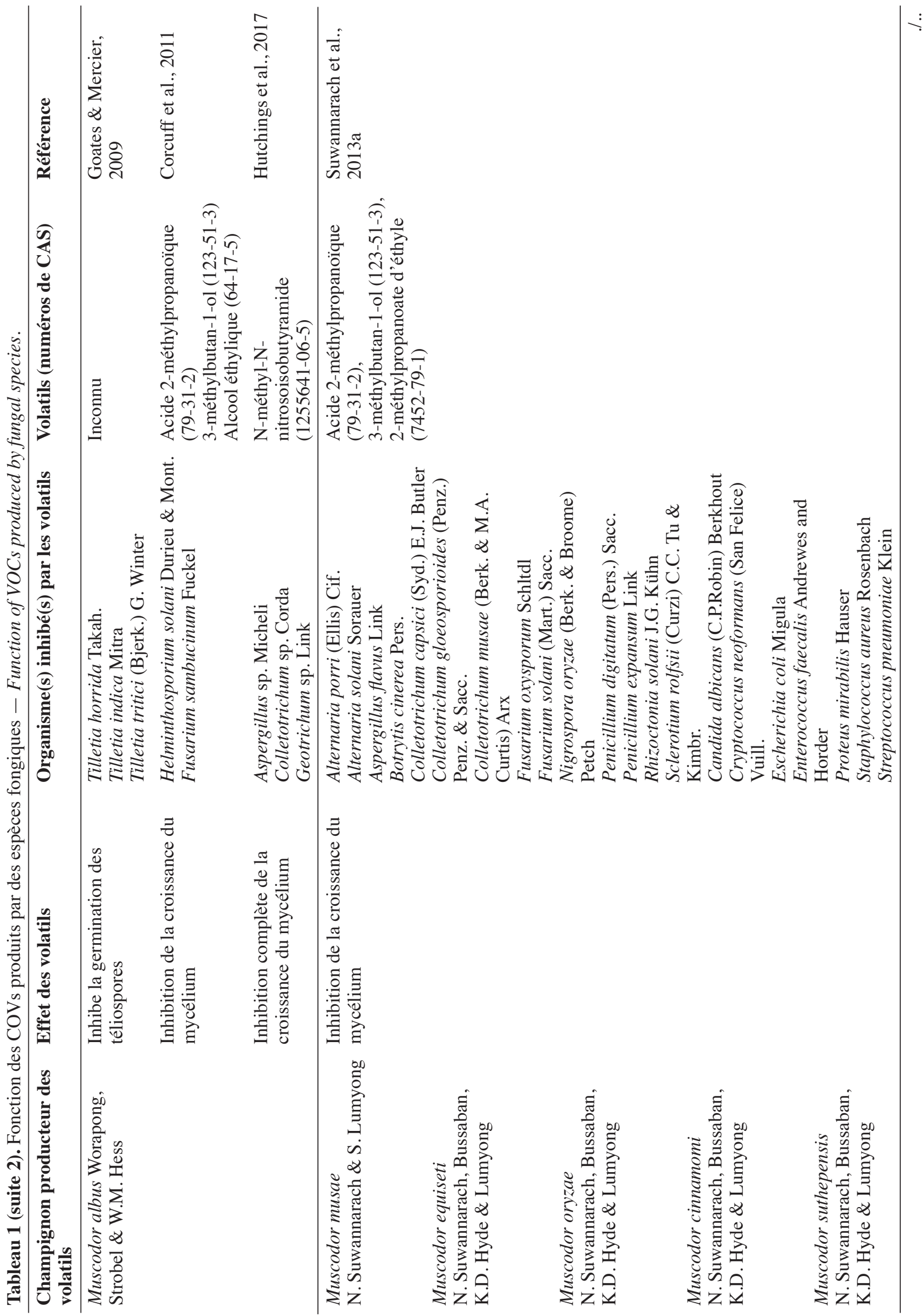




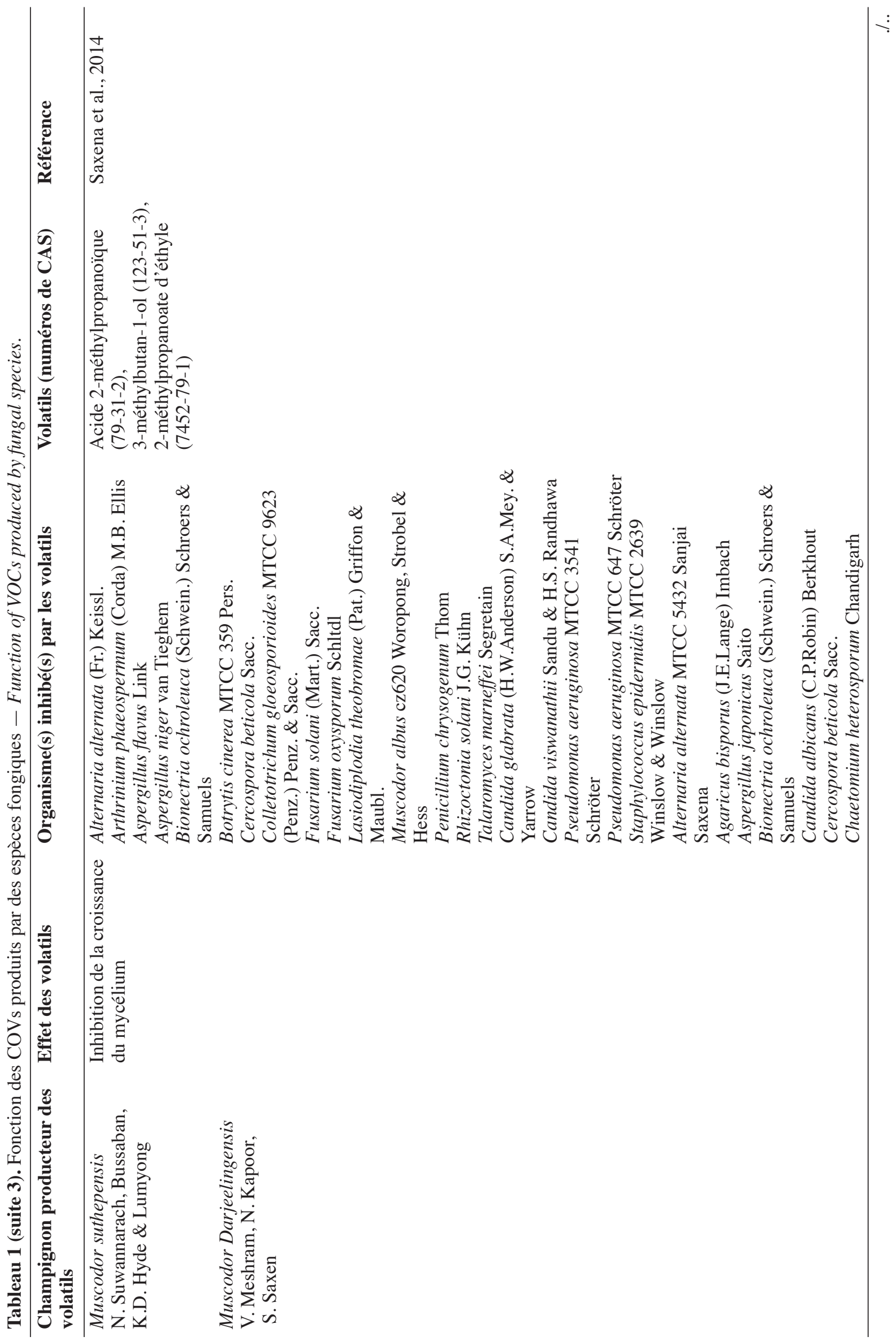




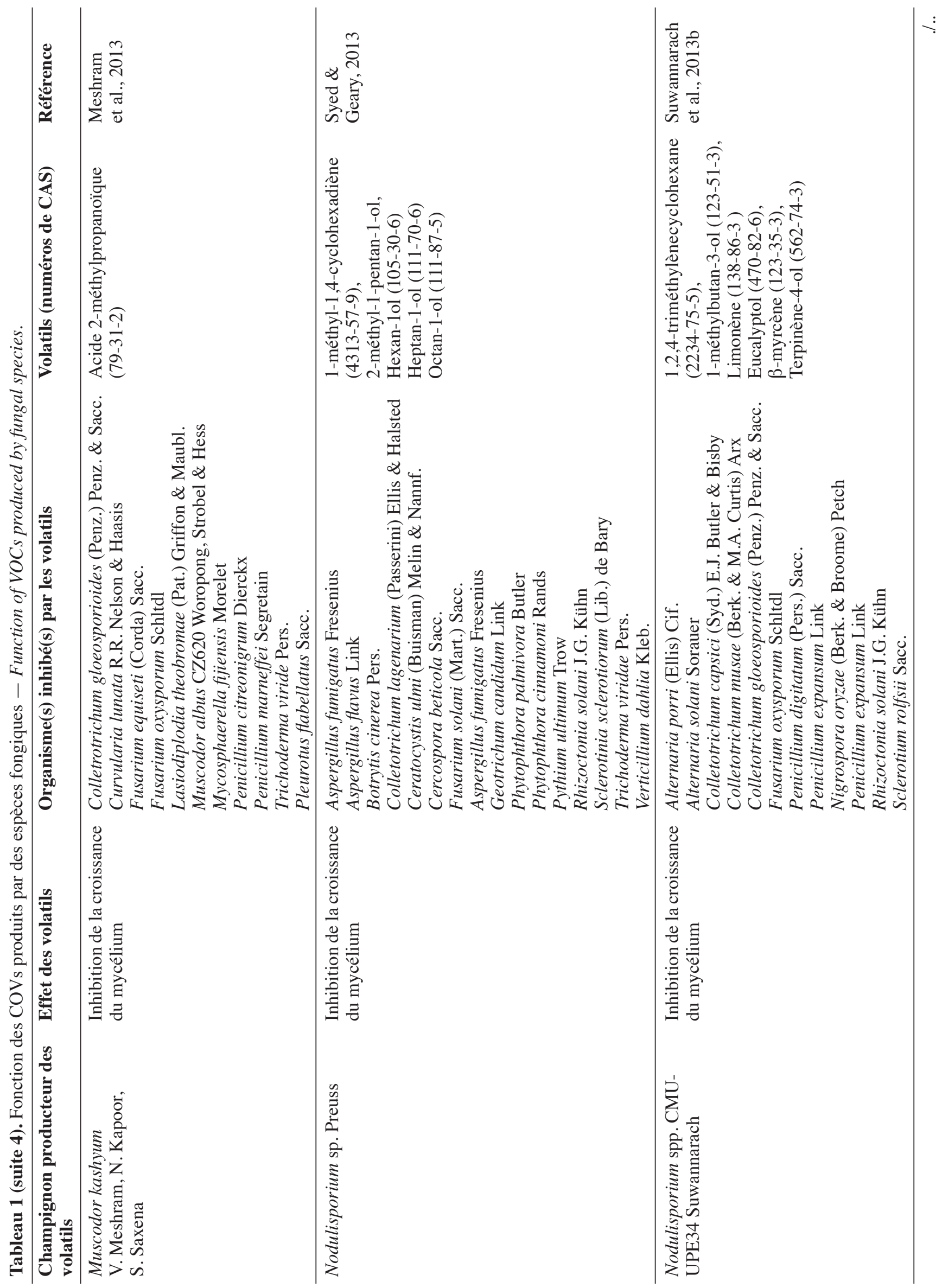




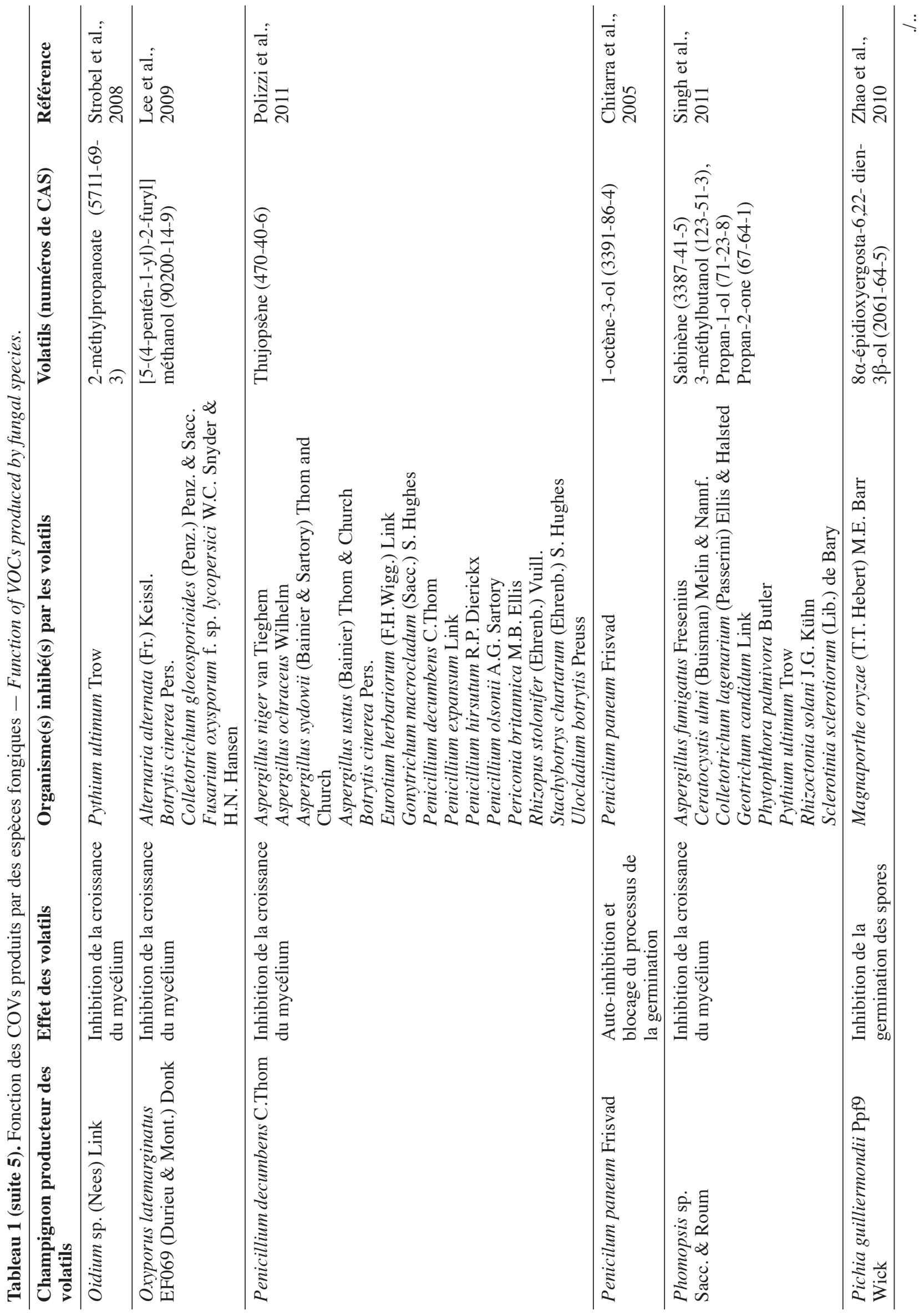




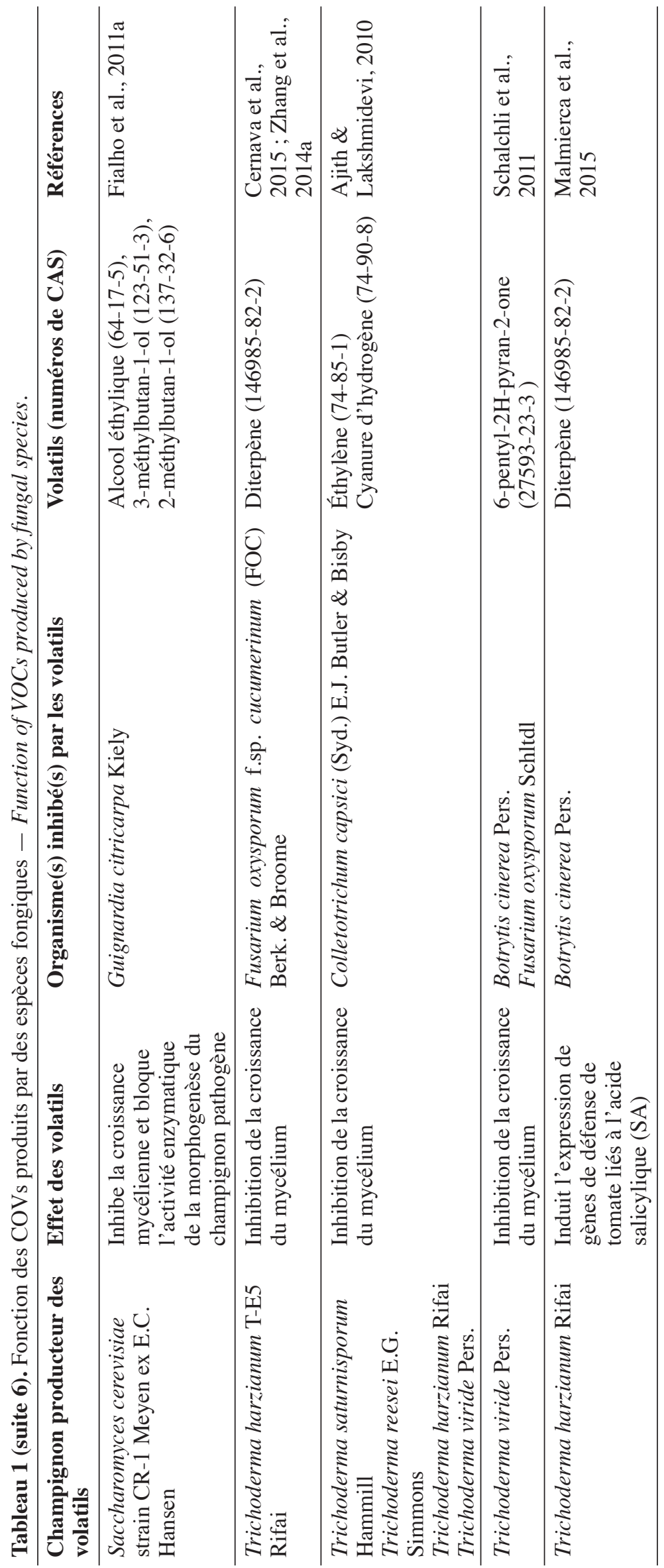

chimiques du sol, les caractéristiques fongiques, la composition microbienne, les activités métaboliques des différents sols et les changements environnementaux. Toutes ces études ont eu pour objectif l'explication du mécanisme de la fongistase du sol (Lockwood \& Langston Jr, 1964 ; Dobbs \& Gash, 1965; Romine \& Baker, 1973 ; Lockwood, 1977).

À la fin des années 1990, les études se sont orientées vers certaines bactéries spéciales, en particulier les Pseudomonas Migula et leurs métabolites, dévoilant ainsi le rôle joué par ces bactéries dans la suppression des maladies fongiques des plantes transmises par le sol. En 2004, Chuankun révèle la présence de six composés organiques volatils (N,N-diméthyl-méthanamine, 3-méthyl-2-pentanone, disulfure de diméthyle, méthylpyrazine, 2,5-diméthylpyrazine, N-diméthyloctylamine et nonadécane) dans les sols, capables d'inhiber trois espèces fongiques, Paecilomyces lilacinus Thom, Pochonia chlamydospora Goddard et Clonostachys rosea Link, ce qui laisse supposer l'existence de composés volatils d'origine fongique répandus dans le sol.

Dans la plupart de ces études, la fongistase a été quantifiée sur la base de la germination des spores par observation microscopique. Les spores sont généralement incubées directement dans les sols ou sur des matériaux qui ont été en contact permanent ou temporaire avec le sol autoclavé. Après une période d'incubation, le pourcentage de germination des spores peut être déterminé au microscope (Hora et al., 1977 ; Al-Khaliel, 2010).

À côté de la germination des spores, la croissance hyphale a également été utilisée pour les dosages de la fongistase (De Boer et al., 2003). Le contrôle consiste en la croissance ou la germination des spores dans un environnement dépourvu d'éléments nutritifs comme du sable purifié, dans lequel les champignons doivent utiliser des nutriments endogènes pour favoriser 
la germination ou la croissance des hyphes, ce qui explique le potentiel fongistatique existant dans le sol.

En 2007, Zou et al. ont découvert que des mélanges de certaines bactéries du sol apparemment non antagonistes pourraient avoir aussi un fort effet négatif sur la croissance des champignons in vitro.

À ce jour, plus de 500 bactéries et champignons ont été décrits comme producteurs de COVs et environ 1000 COVs ont été compilés dans DOVEMO (base de données des substances volatiles émises par les microorganismes) (Lemfack et al., 2017). Le sol présente l'un des principaux habitats des bactéries et des champignons. Ces composés parcouraient de longues distances dans les pores du sol, bloquant ainsi la germination et/ou affectant la synthèse des protéines des champignons nuisibles (Wheatley, 2002 ; Effmert et al., 2012 ; Morath et al., 2012).

Dans cette revue, nous allons nous intéresser aux travaux réalisés sur les champignons afin d'envisager leurs potentialités antifongiques et décrypter leurs modes d'action grâce aux COVs. Ceux-ci inhibent les espèces fongiques pathogènes, créant ainsi un microenvironnement qui leur est défavorable et impliquant d'autres phénomènes tels que l'apoptose et l'activité fongicide.

\subsection{Rôle et modes d'action des COVs fongiques}

La plupart des COVs appartiennent à quatre groupes chimiques : les terpénoïdes, les phénylpropanoïdes et les dérivés d'acides gras et d'acides aminés (Dudareva et al., 2013 ; Delory et al., 2016). Dans cette revue, en raison du grand nombre de recherches et de leur importance, nous évoquerons seulement le rôle joué par les COVs mono- et sesquiterpéniques et les COVs appartenant aux alcools et acides carboxyliques.

Les COVs terpéniques. Les composés terpéniques forment le type commun le plus important des COVs émis par les espèces végétales et fongiques dans le sol. Ces composés (mono- et sesquiterpéniques) modulent les interactions souterraines entre les champignons et les plantes (Fiers et al., 2013). Ils joueraient un rôle potentiel dans la défense des plantes contre les maladies fongiques.

L'effet antifongique des COVs sesquiterpéniques. Parmi les sesquiterpènes, le farnésol émis par Candida albicans (C. P. Robin) Berkhout affecte la croissance d'Aspergillus nidulans G. Winter, Fusarium graminearum Schwabe, Aspergillus niger van Tieghem et Aspergillus fumigatus Fresenius, en induisant leur apoptose et en empêchant le développement des conidies. Selon l'étude menée par Hornby \& Nickerson (2004), ce composé a montré aussi un effet d'auto- inhibition de la germination de C.albicans en cas de densité trop élevée (Hornby \& Nickerson, 2004).

Dans le même contexte, le thujospène, étant un sesquiterpène émis par Penicillium decumbens C.Thom, est connu pour sa fonction autorégulatrice, exerçant dans un premier temps l'auto-inhibition des spores de P.decumbens lors d'un surpeuplement et, dans un deuxième temps, inhibant plusieurs autres espèces et genres suite à la compétition causée par un manque de nutrition et ce, afin de satisfaire à ses besoins (Tableau 1). Cette molécule est capable de traverser les parois et les membranes cellulaires et de perturber les fonctions vitales des spores (les systèmes de transport ionique, le transport des électrons et le $\mathrm{pH}$ ) (Chami et al., 2005).

À l'instar du thujospène, les espèces de Trichoderma Persoonémettent plusieurs sesquiterpènes.Parexemple, Trichoderma arundinaceum Zafari, Gräfenhan \& Samuels, lors de la biosynthèse de hazariuma A (HA), secrète le trichodiène. $\mathrm{Ce} \mathrm{COV}$ inhibe indirectement Botrytis cinerea Pers. en induisant l'expression de gènes de défense codant pour la production de l'acide salicylique et l'acide jasmonique et en interagissant avec des enzymes hydrolytiques (Malmierca et al., 2012).

L'effet antifongique des COVs monoterpéniques. En ce qui concerne les monoterpènes, le Nodulisporium sp. CMU-UPE34 Preuss émet 31 COVs dont le 1,8-cinéole et le terpinène-4-ol qui constituent les deux composants majeurs identifiés. Le Nodulisporium sp. CMU-UPE34 montre une efficacité importante (entre 47 et $93 \%$ ) dans la lutte contre Penicillium digitatum (Pers.) Sacc., Penicillium expansum Link, A. fumigatus et Rhizoctonia solani J.G. Kühn. En effet, le 1,8-cinéole inhibe la respiration mitochondriale et les différents stades de la mitose. Cette molécule pénètre à travers la membrane cellulaire et cause des dommages oxydatifs au niveau des organites cellulaires. Cet effet oxydatif de 1,8-cinéole est intensifié par le terpinène-4-ol permettant une inhibition de la croissance de $B$. cinerea en l'atténuant de 99,46\%. Ceci a été expliqué par le fait que le 1,8-cinéole présente une grande affinité avec la membrane, ce qui facilite la pénétration à travers la membrane du terpinène-4-ol et qui cause des lésions au niveau de la membrane perturbée (Yu et al., 2015).

Le 1,8-cinéole constitue aussi le composé majoritaire chez Hypoxylon spp. Bull. Il inhibe un large spectre de champignons (Tableau 1). Cette inhibition varie de $27 \%$ à $93 \%$ pour 14 champignons, tels que Sclerotinia sclerotiorum (Lib.) de Bary et A.fumigatus (Tableau 1) et une inhibition totale de $100 \%$ pour les deux chromistes Phytophthora palmivora Butler et P. cinnamomia Rands (Tomsheck et al., 2010).

De la même façon que Nodulisporium sp., le champignon Phomopsis sp. Sacc. \& Roum. sécrète 
le sabinène monoterpène majoritaire. Ce champignon inhibe un large spectre d'espèces fongiques de différents groupes taxonomiques tels que les champignons anamorphiques, les ascomycètes ainsi que les oomycètes (Tableau 1). Cette inhibition varie entre 5,6 et 70,7 \% . D'après Singh et al. (2011), un essai sur plaque de Petri a montré une réduction de la croissance radiale du mycélium de $S$. sclerotiorum (70,7\%), Pythium ultimum Trow (59,1\%), A. fumigatus (57\%), R. solani (53\%) et Geotrichum candidum Link $(45,3 \%)$. Ce champignon inhibe aussi la croissance et la sporulation d'Altenaria alternata (Fr.) Keissl.

Dans la même optique, une étude comparative entre 13 monoterpènes a montré que le limonène est le composé majeur sécrété par Fusarium oxysporum Schltdl. Ce dernier est responsable de l'inhibition totale de quatre espèces fongiques, $R$. solani, $F$. oxysporum, P. digitatum et A.niger. Ceci a été prouvé par l'inhibition de la sécrétion de la pectine méthylestérase, la cellulase et les polyphénols oxydases. Fusarium oxysporum est connu pour sa production de COVs. Ces derniers inhibent la croissance de $B$. cinerea et $S$. sclerotiorum in vitro et sont suppressifs contre la maladie post-récolte de la moisissure grise de la tomate (Zhang et al., 2014b). D'autres études ont indiqué que la production des COVs par F. oxysporum a un effet auto-inhibiteur à la croissance mycélienne et à la germination des spores de cette espèce (Minerdi et al., 2009).

Les COVs alcooliques et carboxyliques. À côté des COVs terpéniques, les alcools et les acides carboxyliques jouent un rôle très important dans la défense des plantes.

L'effet antifongique des COVs appartenant aux alcools. Parmi les COVs se trouvent les alcools sécrétés par des espèces fongiques, notamment Saccharomyces cerevisiae Meyen ex E.C. Hansen (souche CR1) qui sécrète le 3-méthyl-1-butanol, 2-méthyl-1-butanol, mais aussi l'alcool phényléthylique. Ces composés ont pour effet l'inhibition de la croissance mycélienne de Guinardia citricarpa Kiely en raison de la réduction de l'assimilation du glucose par les cellules provoquée par la disponibilité réduite de la source de carbone (Fialho et al., 2011b). D'autres études menées sur ces alcools ont montré qu'une fois appliqués à G. citricarpa, ils diminuent l'activité des acétyle CoA carboxylases (ACCase) EC 6.4.1.2 et des tyrosinases EC 1.14.18.1 qui jouent un rôle dans la morphogenèse fongique, la croissance mycélienne et la formation des conidies. En outre, ces alcools provoquent l'autolyse de G. citricarpa et perturbent le gène codant pour l'activité $\beta$-1,3-glucanase EC 3.2.1.39. Cette autolyse est totale, provoquée par l'augmentation du taux de $\beta$-1,3-glucanase dans la paroi cellulaire qui la dégrade en libérant des monomères de glucose (Wheatley, 2002 ; Fialho et al., 2010).

Par ailleurs, le 1-octène-3-ol constitue le composé le plus abondant du spectre de COVs produits par Penicillium paneum Frisvad, à la suite d'un groupement d'une densité très élevée, dépassant $10^{9}$ spores $\cdot \mathrm{ml}^{-1}$. Cet alcool agit comme un auto-inhibiteur. Il inhibe l'enflure, empêche la formation du tube germinatif (croissance polarisée) et induit la conidiation microcyclique (Chitarra et al., 2005).

L'effet antifongique des COVs appartenant aux acides carboxyliques. En plus des alcools émis par les champignons, nous enregistrons l'importance des acides carboxyliques sécrétés par les champignons endophytes, tels que Muscodor albus Worapong, Strobel \& W.M. Hess (Worapong \& Strobel, 2009). Celui-ci fait l'objet de plusieurs études grâce à la multitude de ses composés carbonés volatils produisant un mélange synergique qui a des effets létaux contre une large variété de plantes et de champignons pathogènes.

À ce jour, 14 espèces de Muscodor ont été décrites. Sur le plan géographique, des espèces de Muscodor ont été signalées en Amérique du Sud et du Nord et dans le sud-est de l'Asie. Malgré cette différence géographique, l'acide 2-méthylpropanoïque présente le composé majeur émis par M. albus, M. crispans A.M. Mitchell, Strobel \& W.M.Hess et M. sutura Kudalkar, Strobel \& Ul-Hassan (Strobel et al., 2001 ; Daisy et al., 2002 ; Grimme et al., 2007 ; Strobel et al., 2008).

Le mécanisme d'action des COVs de M.albus sur les champignons cibles reste une énigme pour les chercheurs. Cependant, une étude d'analyse transcriptomique sur des cellules de Bacillus subtilis Cohn exposées aux COVs de M.albus a montré l'expression de gènes impliqués dans la réparation et la réplication de l'ADN. Ces résultats préliminaires indiqueraient que les COVs de M. albus induisent un certain type de lésions de l'ADN dans les cellules qui causeraient une décondensation des chromosomes dans les bactéries (Strobel et al., 2011). D'après Browning et al. (2006), l'acide 2-méthylpropanoïque provoque aussi une acidification du cytoplasme grâce à sa diffusion rapide à travers la membrane.

Le peu d'informations sur les modes d'action des Muscodor sp. n'a pas empêché les chercheurs d'effectuer de multiples tests sur plusieurs souches afin d'observer le spectre de contrôle des champignons pathogènes. L'espèce M. albus, par exemple, inhibe la croissance de $R$. solani et de Phytophthora capsici Leonian. Cette espèce inhibe aussi la germination des téliospores de Tilletia horrida Takah., T. indica Mitra et T. tritici (Bjerk.) G. Winter, à l'origine respectivement du charbon du riz et de la carie commune du blé (Goates \& Mercier, 2009). D'autres espèces de Muscodor ont fait l'objet d'études sur la lutte contre les 
champignons pathogènes, parmi lesquelles Muscodor cinnamomi Suwannarach, Bussaban, K.D. Hyde \& Lumyong qui contrôle $R$. solani (qui provoque la brûlure des feuilles, les taches foliaires, la fonte des semis et la pourriture des racines) (Suwannarach et al., 2013a), Muscodor kashayum V. Meshram, N. Kapoor \& S. Saxena qui inhibe la croissance des Cercospora beticola Sacc., Colletrotichum gloesporioides Penz. \& Sacc., Mycosphaerella fijiensis Morelet, Chaetomium heterosperum Kunze ex Fr.et $F$. oxysporum (Tableau 1) (Meshram et al., 2013). Des études menées par Saxena et al. (2015) ont montré que la croissance d'Alternaria alternata (Fr.) Keissl. et de Cercospora bataticola Cif. \& Bruner a été complètement inhibée par les composés volatils de Muscodor tigerii S. Saxena, V. Meshram \& N. Kapoor (Saxena et al., 2014).

En outre, dans leurs études, Mercier et al. (2007) et Worapong \& Strobel (2009) ont montré que, grâce au spectre des COVs émis par deux souches, Muscodor CZ-620 et MFC2, le contrôle de la pourriture fongique de multiples fruits est plus efficace (Mercier et al., 2007 ; Worapong \& Strobel, 2009). En 2017, des recherches menées par Hutchings et al. (2017), tout en s'appuyant sur des travaux antérieurs concernant les COVs thermolabiles produits par M.albus (Jimenez et al., 2012), ont permis l'identification d'un nouveau COV, $\mathrm{N}$-méthyl-N-nitrosoisobutyramide (MNIBA), qui est apparu seulement à la suite des analyses de GC-MS par une température d'injection basse $\left(140^{\circ} \mathrm{C}\right)$ (Hutchings et al., 2017). La chromatographie en phase gazeuse couplée à la spectrométrie de masse (GC-MS) est une technique d'analyse qui combine les performances de la chromatographie en phase gazeuse, pour la séparation des composés, et de la spectrométrie de masse, pour la détection et l'identification des composés en fonction de leur rapport masse sur charge. Les produit élués en GC sont envoyés un par un vers le spectromètre de masse afin de permettre l'identification des COVs. En premier lieu, les résultats ont montré que la toxicité de Muscodor sp. vis-à-vis de la souche d'Escherichia coli varie selon la concentration de MNIBA dans le profil de panels des COVs émis par l'espèce de Muscodor.

En deuxième lieu, ces recherches ont démontré, au travers des tests d'analyse de la bioactivité, que le facteur dominant provoquant la toxicité chez M. albus est sa capacité à synthétiser MNIBA. Cette molécule endommage le fonctionnement de l'ADN et cause sa méthylation. D'ailleurs, MNIBA est considéré comme un $\mathrm{N}$-nitroso-composé très proche chimiquement du N-méthyl-N-nitrosourea (MNU). Il est considéré comme l'un de ses produits dérivés responsable d'une décomposition spontanée du méthyldiazonium, réactif qui est capable de méthyler l'ADN. MNIBA est capable de se décomposer spontanément pour former l'acide isobutyrique et le méthyl-diazohydroxide qui se convertit par la suite en acide méthyldiazonium, capable d'interagir avec les sites nucléophiliques de l'ADN. La production de MNIBA par les isolats de M.albus est très semblable à la production de streptocine. Il serait important de prendre en compte deux facteurs contribuant à l'efficacité d'un agent antimicrobien : sa fraction active et sa capacité d'accéder à sa cible. De surcroît, au niveau de MNIBA, la fraction active est attachée à un dérivé de l'acide isobutyrique, un composé volatil de faible poids moléculaire permettant d'être utilisé en abondance par les isolats, qui explique aussi son abondance lors de l'analyse des spectres des COVs des Muscodor par GC-MS.

Cependant, les champignons Muscodor sp. sont nécessaires en tant que source de biofumigation et sont capables d'inhiber le développement de plusieurs champignons pathogènes, contribuant ainsi au contrôle des maladies fongiques des plantes.

\section{LA MYCOFUMIGATION}

Le contrôle des maladies fongiques repose encore sur les fongicides chimiques. Cependant, plusieurs ne sont plus utilisés à cause des risques toxicologiques et de l'apparition de souches résistantes aux fongicides. Ces raisons ont augmenté le besoin de stratégies alternatives de contrôle. Parmi celles-ci, on trouve l'utilisation des microorganismes tels que les bactéries, les levures et les champignons.

L'exploitation des champignons endophytes comme source importante de COVs (mycofumigant ou biofumigant) est une approche prometteuse dans la protection des cultures contre les phytopathogènes fongiques. La mycofumigation est l'une des alternatives pouvant remplacer l'utilisation de certaines substances dangereuses, mais le potentiel d'utilisation dépend aussi de la souche, de ses effets et de son (ses) mode(s) d'utilisation. Elle représente une nouvelle technique biologique réduisant la main-d'œuvre, si on la compare à la pulvérisation d'une solution aqueuse chimique pour contrôler les maladies. En effet, les COVs sont des agents antifongiques idéaux, qui peuvent agir à distance sur un large spectre de pathogènes. À partir de l'interaction proximale, leur champ d'activité s'étend par diffusion aqueuse sur de plus grandes distances que par diffusion dans l'air, y compris dans les pores du sol (Wheatley, 2002).

Cependant, l'efficacité des COVs varie selon l'espèce de champignon, la quantité d'inoculum utilisée et le type de maladie post-récolte. Par exemple, l'étude réalisée par Suwannarach et al. (2016) a montré qu'une fumigation de $12 \mathrm{~h}$ avec $30 \mathrm{~g}$ par $4 \mathrm{~L}$ d'inoculum de Muscodor suthepensis Suwannarach, Bussaban, K.D. Hyde \& Lumyong a fourni un contrôle complet de la pourriture de la mandarine causée par P. digitatum (Suwannarach et al., 2016). De même, il a 
fallu $24 \mathrm{~h}$ de fumigation de $30 \mathrm{~g}$ par $11,4 \mathrm{~L}$ de culture de $M$. albus pour un contrôle complet de P. digitatum, ainsi que pour le contrôle de la moisissure bleue causée par P. expansum et de la moisissure grise causée par B. cinerea sur la pomme. Une fumigation avec $140 \mathrm{~g}$ par 11,4 L d'inoculum de M. albus a également contrôlé la pourriture brune de la pêche causée par Monilinia fructicola (G.Winter) Honey (Mercier \& Jiménez, 2004 ; Mercier \& Smilanick, 2005).

Cette technique a été développée après avoir testé sur le terrain, en serre et en plein air, la fumigation des sols avec les champignons mycofumigants M. albus (Grimme et al., 2007). Cette méthode de fumigation consiste à inoculer les grains d'orge avec $M$. albus puis à les broyer afin de donner une texture de sciure de bois (avec une taille de particules moyenne d'environ $300 \mu \mathrm{m}$ ) à l'aide d'un mélangeur. Une fois le M. albus formulé et préparé selon la méthode de Quimby (Quimby Jr et al., 1999), l'orge moulue est répartie sur la surface de la terre en utilisant un épandeur d'engrais à raison de $480 \mathrm{~kg} \cdot \mathrm{ha}^{-1}$, paillis par la suite par du plastique noir. Une couche de sol meuble de $5 \mathrm{~cm}$ d'épaisseur a ensuite été appliquée avec une litière mécanique. Une couche de paillis au-dessus de la couche de M. albus a colonisé l'orge. Ces recherches ont montré que plus de $88,8 \%$ des plantules de betterave à sucre ont survécu après la mycofumigation des sols par le M.albus infestés par R. solani, P. ultimum ou Aphanomyces cochlioides Drechsler (Stinson et al., 2003a ; Grimme et al., 2007)

Afin de valoriser l'utilisation de M.albus, AgraQuest, une société de biotechnologie agricole en Californie, a développé l'utilisation de ce champignon pour la lutte préventive contre la moisissure grise des tomates, des pommes, des fraises (Strobel et al., 2010) et aussi pour lutter contre les maladies post-récolte, afin de contrôler la moisissure bleue, la moisissure grise des pommes, la pourriture brune des pêches et grise des vignes où les COVs apparaissent sûrs, efficaces et respectueux de l'environnement. Cette technique a pour but également de remplacer le bromure de méthyle qui est utilisé pour la stérilisation des sols en raison de sa toxicité et de ses influences négatives sur la couche d'ozone (Lacey et al., 2009 ; Morgenstern, 2014).

D'autres études in vitro préliminaires ont porté sur l'utilisation de champignons endophytes comme mycofumigants, par exemple l'utilisation de Nodulisporium sp. Preuss. Des expériences in vivo au laboratoire ont montré que 50 et $60 \mathrm{~g}$ de Nodulisporium sp. CMU-UPE34 mélangés avec du riz au jasmin, qui est une variété d'Oryza indica, dans un bac de $4 \mathrm{~L}$ contenant trois citrons inoculés par $P$. digitatum ou $P$. expansum, contrôlent complètement la putréfaction verte et la moisissure bleue sur Citrus aurantifolia, $C$. reticulata et $C$. limon (Suwannarach et al., 2013a ; Suwannarach et al., 2016).
La fumigation d'un contenu de quatre pommes inoculées par P. expansum dans un récipient de 6,5 L, avec une culture de $50 \mathrm{~g}$ de Nodulisporium sp. CF016 et avec du son de blé/riz, supprime le développement des lésions de la moisissure grise et de la moisissure bleue sur les pommes, respectivement de 88 et $76 \%$.

De même, l'utilisation in vivo de $50 \mathrm{~g}$ de son de blé/riz inoculés par Oxyporus latemarginatus EF069 (Durieu \& Mont.) Donk, dans un récipient de $7 \mathrm{~L}$ contenant cinq pommes, a réduit efficacement de $98,4 \%$ le développement de la pourriture grise des pommes en post-récolte causée par B. cinerea (Lee et al., 2009).

\section{L'EFFET DES COVS SYNTHÉTIQUES SUR LES CHAMPIGNONS PATHOGÈNES}

Afin de mieux comprendre l'effet antifongique des COVs sur les champignons pathogènes, les chercheurs ont eu recours à des molécules synthétiques. Ils les ont comparées avec les COVs sécrétés directement par les champignons. Nous avons pris comme exemple l'étude menée par Syed \& Geary (2013). Selon cette étude, la comparaison de COVs fongiques avec un mélange de COVs synthétiques constitué de pentan-2-one, hexan3 -one, 1,8-cinéole, $\beta$-farnésène et d'acide propanoïque, a montré que ce mélange était plus efficace contre P. palmivora, P. cinnamomi, P. ultimum, R. solani, $S$. sclerotiorum et $B$. cinerea.

Par ailleurs, Singh et al. (2011) ont montré que l'utilisation de la concentration efficace médiane (CE50) d'un mélange artificiel semblable aux COVs émis par Phomopsis sp. Sacc. \& Roum. inhibe $100 \%$ des champignons testés et marque une sensibilité de Colletotrichum lagenarium (Passerini) Ellis \& Halsted et Trichoderma viride Pers., contrairement aux COVs naturels qui enregistrent une inhibition variant de 5,6 à $70,7 \%$ et aucune inhibition chez $T$. viride ou C. lagenarium. Cela suggère que certains COV émis par Phomopsis sp. sont non identifiés par le GC-MS à cause de leurs faibles concentrations, n'atteignant pas le seuil de détection. L'impureté du bouquet de COVs secrétés par Phomopsis sp. diminue l'effet inhibiteur du champignon par rapport à l'effet inhibiteur des molécules synthétiques. Dans le même contexte, l'utilisation d'un produit chimique pur ou d'un mélange de plusieurs de ces produits chimiques purs (le butyle, l'acétate d'éthyle et l'éthanol représentant $97 \%$ du spectre de COVs naturellement émis par Ceratocystis fimbriata [Passerini] Ellis \& Halsted), selon des proportions calculées à l'aide de l'analyse par GC-MS, n'a montré aucun effet d'inhibition. Selon les auteurs, l'inhibition peut être un effet synergique de tous les COVs de $C$. fimbriata y compris ceux qui ne peuvent pas être détectés par 
les méthodes d'identification actuelles à cause de leur fragilité (Li et al., 2015). Ceci est similaire aux résultats d'autres COVs produits par Muscodor sp. À cet égard, une étude réalisée par Fiers et al. (2013) sur l'effet des COVs émis par les racines de l'orge infectées par Cochliobolus sativus (S. Ito \& Kurib.) Drechsler ex Dastur, dans une atmosphère modifiée, a révélé que ces racines d'orge infectées ont réduit la croissance de $C$. sativus de 13 à $17 \%$ dans la même enceinte par rapport aux champignons exposés aux racines d'orge saines (Fiers et al., 2013). En se basant sur l'identification de ces composés, Kaddes et al. (2016) ont sélectionné le méthyle acrylate (MA) et le méthylpropionate (MP) qui sont deux molécules dont les pics étaient les plus intenses. L'utilisation du MA inhibe $100 \%$ de la croissance de cinq champignons testés, C. sativus, Fusarium culmorum (Wm.G.Sm.) Sacc., F. graminearum, P. digitatum et P. expansum. L'effet du MP a été moins prononcé en inhibant de $21,3 \%$ la croissance de $P$. expansum et en provoquant une croissance de $150 \%$ chez F. graminearum, comparé aux autres champignons testés (Kaddes et al., 2016).

\section{TOXICITÉ DES COMPOSÉS ORGANIQUES VOLATILS}

\subsection{L'effet phytotoxique des COVs}

Malgré tous les résultats prometteurs sur les COVs, la question de la phytotoxicité de l'utilisation des COVs reste toujours fort inquiétante pour les chercheurs. De nombreuses études ont démontré l'existence de fortes relations entre les COVs et la phytotoxicité (Arimura et al., 2010). Dès 1965, Muller a prouvé que les COVs terpéniques sécrétés par les feuilles de S. leucophylla Raf. pourraient réduire le nombre de radicules et la germination de l'hypocotyle des graines de Cucumis sativus L. Une constatation tirée aussi par Inderjit a révélé que la richesse des espèces végétales était beaucoup plus faible à cause des COVs produits par la litière d'Ageratina adenophora (Spreng.) King \& H.Rob. (Evans et al., 2011).

Dans le même contexte, He et al. (2014) ont montré que les COVs contenus dans l'eau du sol provenant de la lixiviation des feuilles mortes et de la décomposition des résidus autour d'Eucalyptus urophylla S.T.Blake sont majoritairement des monoterpènes et des sesquiterpènes (He et al., 2014). Ces sesquiterpènes, dont le 1,8-cinéole et le terpinène-4-ol, qui représentent respectivement $19 \%$ et $39 \%$ de l'hydrosoluble, testés sous leur forme de synthèse, inhibent la germination de quelques grains tels que ceux du raygrass annuel ainsi que la croissance des racines de certaines mauvaises herbes (Abrahim et al., 2000).
De son côté, Ogura et al. (2000) se sont intéressés à l'effet phytotoxique des alcools et plus précisément la géosmine émise par $P$. expansum, alcool bicyclique responsable de l'odeur typique de la terre. Cet alcool artificiel testé par Ogura et al. (2000) à une concentration de $100 \mathrm{mg} \cdot \mathrm{l}^{-1}$ inhibe complètement la germination des grains de 15 variétés de Brassicaceae, dont 6 de radis.

Cette étude a été suivie par celle de Lee et al. (2014), qui s'est intéressée également à l'effet phytotoxique des COVs d'origine alcoolique dans leur phase gazeuse. L'exposition des grains et des plantules d'Arabidopsis thaliana L. à une concentration de $1 \mathrm{ppm}$ de la géosmine, octan-1-ol, octan-2-ol, octan3-ol et 1-octène-3-ol sous leurs formes synthétiques, n'a montré aucun effet sur la germination. Par contre, leur exposition à la géosmine a entrainé un arrêt de croissance de la radicule (Lee et al., 2014).

Par ailleurs, leur exposition à l'éthanol commercial et l'isopropanol commercial a induit des changements morphologiques indésirables (déformation et diminution de la taille des feuilles, réduction de leur concentration en chlorophylle), de même qu'une réduction de la croissance des racines des plantules traitées (Lee et al., 2014).

\subsection{L'effet toxique des COVs sur les applicateurs}

À côté de ces effets phytotoxiques, de nombreux COVs synthétiques tels que le benzène, le toluène, l'éthylbenzène et le xylène (BTEX) sont responsables aussi de graves risques pour la santé humaine, autant pour les agriculteurs que les consommateurs.

Selon l'Agence Américaine de la Protection de l'Environnement, les travailleurs exposés fréquemment à ces composants BTEX risquent d'avoir une irritation de la peau, une dépression du système nerveux central et des effets nocifs sur le système respiratoire. Une exposition à long terme au BTEX a pour conséquence une affection des systèmes rénaux, hépatiques et sanguins (BTEX Material Data Safety Sheet, 2009). D'après la même source, des études épidémiologiques sur les travailleurs exposés aux benzènes ont montré que ce $\mathrm{COV}$ est cancérogène pour les travailleurs exposés à des concentrations élevées dans les milieux de travail, présentant ainsi des taux de leucémie accrus (USEPA Air Toxics, 2009).

D'autres études ont montré que l'exposition au naphtalène, considéré comme COV appartenant aux hydrocarbures aromatiques polycycliques, provoque une anémie hémolytique (dégradation anormale des globules rouges) (Siegel \& Wason, 1986) et à des lésions de la rétine (Amoore \& Hautala, 1983).

À coté des hydrocarbures, il y a d'autres études qui se sont intéressées à l'effet des COVs alcooliques, parmi lesquelles celle d'Inamdar et al. (2012), montrant qu'une fois les cellules souches embryonnaires 
humaines vivantes exposées au 1-octène-3-ol à 1000 ppm, ces cellules meurent.

D'après Guiness et al. (2009), en raison de leur structure chimique, les COVs sont extrêmement résistants aux processus de décomposition naturelle et, une fois rejetés dans l'environnement, ils peuvent persister pendant des années, voire des décennies. Ils sont responsables de graves risques pour la santé humaine dont l'exposition peut se produire soit par ingestion (eau potable provenant de puits contaminés), soit par inhalation (exposition à l'eau contaminée par le biais d'une douche ou d'un lavage) (McGuinness \& Dowling, 2009).

En conclusion, l'effet toxique des COVs demeure relatif et dépendant de plusieurs paramètres tels que la dose, l'origine, la nature chimique et le mode d'exploitation des COVs.

\section{CONCLUSIONS}

Dans cette revue de la littérature, nous avons voulu rassembler toutes les informations disponibles sur l'activité antifongique à médiation volatile des champignons. La littérature disponible sur les COVs émis par les champignons montre que leur diffusion conduit à l'arrêt de la croissance ou à la mort des champignons pathogènes. À cet effet, l'émission des COVs antifongiques apparait comme une alternative prometteuse dans la lutte contre les phytopathogènes fongiques, indépendamment de leurs origines, de leurs doses et de leurs utilisations.

Pour prolonger cette synthèse, nous recommandons en premier lieu d'étudier en détail les techniques optimales de production d'inoculum dans le but de trouver des biofumigants permettant de remplacer les produits chimiques fongicides. En deuxième lieu, l'identification des molécules actives est nécessaire afin de fournir des indices sur d'éventuels mécanismes d'action. Une autre façon d'élucider ces mécanismes serait d'observer les changements qui se produisent au niveau de l'expression des gènes (transcriptomique) ou des protéines (protéomique) après exposition à des matières volatiles fongiques.

\section{Remerciements}

Les auteurs mentionnent que cette recherche n'a reçu aucun financement. Les auteurs voudraient remercier Dr Mourad Kadddes et Dr Imen Ben Taher pour leurs apports scientifiques.

\section{Bibliographie}

Abrahim D., Braguini W.L., Kelmer-Bracht A.M. \& IshiiIwamoto E.L., 2000. Effects of four monoterpenes on germination, primary root growth, and mitochondrial respiration of maize. J. Chem. Ecol., 26, 611-624.

Ajith P. \& Lakshmidevi N., 2010. Effect of volatile and non-volatile compounds from Trichoderma spp. against Colletotrichum capsici incitant of anthracnose on bell peppers. Nat. Sci., 8, 265-269.

Al-Khaliel A.S., 2010. Effects of arbuscular mycorrhization in sterile and non-sterile soils. Trop. Life Sci. Res., 21, 55.

Amoore J.E. \& Hautala E., 1983. Odor as an ald to chemical safety: odor thresholds compared with threshold limit values and volatilities for 214 industrial chemicals in air and water dilution. J. Appl. Toxicol., 3, 272-290, doi. org/10.1002/jat.2550030603

Arimura G.-I., Shiojiri K. \& Karban R., 2010. Acquired immunity to herbivory and allelopathy caused by airborne plant emissions. Phytochemistry, 71, 16421649, doi.org/10.1016/j.phytochem.2010.06.021

Berendsen R. et al., 2013. Effects of the mushroom-volatile 1-octen-3-ol on dry bubble disease. Appl. Microbiol. Biotechnol., 97, 5535-5543, doi.org/10.1007/s00253013-4793-1

Browning M. et al., 2006. Potential of butyric acid for control of soil-borne fungal pathogens and nematodes affecting strawberries. Soil Biol. Biochem., 38, 401-404, doi.org/10.1016/j.soilbio.2005.05.020

BTEX Material Data Safety Sheet. www.mathesontrigas. $\mathrm{com} / \mathrm{pdfs} / \mathrm{msds} / \mathrm{math0082}$.pdf, (July 3, 2009).

Cernava T. et al., 2015. A novel assay for the detection of bioactive volatiles evaluated by screening of lichen-associated bacteria. Front. Microbiol., 6, doi. org/10.3389/fmicb.2015.00398

Chami F. et al., 2005. Oregano and clove essential oils induce surface alteration of Saccharomyces cerevisiae. Phytother. Res., 19, 405-408, doi.org/10.1002/ptr.1528

Chitarra G.S., Abee T., Rombouts F.M. \& Dijksterhuis J., 2005. 1-Octen-3-ol inhibits conidia germination of Penicillium paneum despite of mild effects on membrane permeability, respiration, intracellular $\mathrm{pH}$, and changes the protein composition. FEMS Microbiol. Ecol., 54, 6775, doi.org/10.1016/j.femsec.2005.02.013

Chuankun X., Minghe M., Leming Z.\& Keqin Z., 2004. Soil volatile fungistasis and volatile fungistatic compounds. Soil Biol. Biochem., 36, 1997-2004, doi.org/10.1016/j. soilbio.2004.07.020

Corcuff R., Mercier J., Tweddell R. \& Arul J., 2011. Effect of water activity on the production of volatile organic compounds by Muscodor albus and their effect on three pathogens in stored potato. Fungal Biol., 115, 220-227, doi.org/10.1016/j.funbio.2010.12.005

Daisy B. et al., 2002. Muscodor vitigenus anam. sp. nov., an endophyte from Paullinia paullinioides. Mycotaxon, 84, 39-50, doi.org/10.1364/ol.28.002067

De Boer J.F. et al., 2003. Improved signal-to-noise ratio in spectral-domain compared with time-domain optical coherence tomography. Opt. Lett., 28, 2067-2069. 
De Moraes C.M., Mescher M.C. \& Tumlinson J.H., 2001. Caterpillar-induced nocturnal plant volatiles repel conspecific females. Nature, 410, 577-580, doi. org/10.1038/35069058

Delory B.M., Delaplace P., du Jardin P. \& Fauconnier M.L., 2016. Barley (Hordeum distichon L.) roots synthesise volatile aldehydes with a strong age-dependent pattern and release (E)-non-2-enal and (E, Z)-nona-2, 6-dienal after mechanical injury. Plant Physiol. Biochem., 104, 134-145, doi.org/10.1016/j.plaphy.2016.03.028

Dobbs C.G. \& Gash M.J., 1965. Microbial and residual mycostasis in soils. Nature, 207, 1354-1356, doi. org/10.1038/2071354a0

Dobbs C. \& Hinson W., 1953. A widespread fungistasis in soils. Nature, 172, 197-199, doi.org/10.1038/172197a0

Dudareva N., Negre F., Nagegowda D.A. \& Orlova I., 2006. Plant volatiles: recent advances and future perspectives. Crit. Rev. Plant Sci., 25, 417-440, doi. org/10.1080/07352680600899973

Dudareva N., Klempien A., Muhlemann J.K. \& Kaplan I., 2013. Biosynthesis, function and metabolic engineering of plant volatile organic compounds. New Phytol., 198, 16-32, doi.org/10.1111/nph.12145

Effmert U., Kalderás J., Warnke R. \& Piechulla B., 2012. Volatile mediated interactions between bacteria and fungi in the soil. J. Chem. Ecol., 38, 665-703, doi. org/10.1007/s10886-012-0135-5

Evans H. et al., 2011. Volatile chemicals from leaf litter are associated with invasiveness of a neotropical weed in Asia. Ecology, 92, 316-324, doi.org/10.1890/10-0400.1

Ezra D. \& Strobel G.A., 2003. Effect of substrate on the bioactivity of volatile antimicrobials produced by Muscodor albus. Plant Sci., 165, 1229-1238, doi. org/10.1016/s0168-9452(03)00330-3

Fialho M.B. et al., 2010. Volatile organic compounds produced by Saccharomyces cerevisiae inhibit the in vitro development of Guignardia citricarpa, the causal agent of citrus black spot. World J. Microbiol. Biotechnol., 26, 925-932, doi.org/10.1007/s11274-0090255-4

Fialho M.B., $\quad$ Ferreira L.F.R., Monteiro R.T.R. \& Pascholati S.F., 2011a. Antimicrobial volatile organic compounds affect morphogenesis-related enzymes in Guignardia citricarpa, causal agent of citrus black spot. Biocontrol Sci. Technol., 21, 797-807, doi.org/10. 1080/09583157.2011.580837

Fialho M.B., Moraes M.H.D.d., Tremocoldi A.R. \& Pascholati S.F., 2011b. Potential of antimicrobial volatile organic compounds to control Sclerotinia sclerotiorum in bean seeds. Pesquisa Agropecuária Bras., 46, 137-142, doi.org/10.1590/s0100204x2011000200004

Fiers M., Lognay G., Fauconnier M.-L. \& Jijakli M.H., 2013. Volatile compound-mediated interactions between barley and pathogenic fungi in the soil. PLoS One, 8, e66805, doi.org/10.1371/journal.pone.0066805
Fisher M.C. et al., 2012. Emerging fungal threats to animal, plant and ecosystem health. Nature, 484, 186-194, doi. org/10.1038/nature 10947

Friedman M., Henika P.R. \& Mandrell R.E., 2002. Bactericidal activities of plant essential oils and some of their isolated constituents against Campylobacter jejuni, Escherichia coli, Listeria monocytogenes, and Salmonella enterica. J. Food Prot., 65, 1545-1560, doi. org/10.4315/0362-028x-65.10.1545

Goates B.J. \& Mercier J., 2009. Effect of biofumigation with volatiles from Muscodor albus on the viability of Tilletia spp. teliospores. Can.J. Microbiol., 55, 203-206, doi.org/10.1139/w08-104

Grimme E. et al., 2007. Comparison of Muscodor albus volatiles with a biorational mixture for control of seedling diseases of sugar beet and root-knot nematode on tomato. Plant Dis., 91, 220-225, doi.org/10.1094/ pdis-91-2-0220

Hammer K., Carson C. \& Riley T., 2003. Antifungal activity of the components of Melaleuca alternifolia (tea tree) oil. J. Appl. Microbiol., 95, 853-860, doi.org/10.1046/ j.1365-2672.2003.02059.x

He H., Song Q., Wang Y. \& Yu S., 2014. Phytotoxic effects of volatile organic compounds in soil water taken from a Eucalyptus urophylla plantation. Plant Soil, 377, 203215, doi.org/10.1007/s11104-013-1989-1

Hora T., Baker R. \& Griffin G., 1977. Experimental evaluation of hypotheses explaining the nature of soil fungistasis. Phytopathology, 67, 373-379, doi. org/10.1094/phyto-67-373

Hornby J.M. \& Nickerson K.W., 2004. Enhanced production of farnesol by Candida albicans treated with four azoles. Antimicrob. Agents Chemother., 48, 2305-2307, doi. org/10.1128/aac.48.6.2305-2307.2004

Hutchings M.L., Hiller D.A., Berro J. \& Strobel S.A., 2017. Mycofumigation through production of the volatile DNA methylating agent $\mathrm{N}$-methyl-N-nitrosoisobutyramide by fungi in the genus Muscodor. J. Biol. Chem., 292, 73587371, doi.org/10.1074/jbc.m117.779009

Inamdar A.A., Moore J.C., Cohen R.I. \& Bennett J.W., 2012. A model to evaluate the cytotoxicity of the fungal volatile organic compound 1-octen-3-ol in human embryonic stem cells. Mycopathologia, 173, 13-20, doi. org/10.1007/s11046-011-9457-z

Jimenez J.I., Margolis J.S., Baird J.K. \& Lego S.F., 2012. Compounds derived from Muscodor fungi. Google Patents US 2012/0058058 A1 Mar. 8, 2012

Kaddes A. et al., 2016. Volatile Organic Compounds: a new tool to control barley pathogens? Molecules, 21(9), 1124

Kaddes A. et al., 2019. Antifungal properties of two volatile organic compounds on barley pathogens and introduction to their mechanism of action. Int. J. Environ. Res. Public Health, 16, 2866, doi.org/10.3390/ijerph16162866

Koitabashi M., Kajitani Y.\& Hirashima K., 2004. Antifungal substances produced by fungal strain Kyu-W63 from wheat leaf and its taxonomic position. J. Gen. Plant 
Pathol., 70, 124-130, doi.org/10.1007/s10327-0030095-2

Lacey L. et al., 2009. Efficacy of the biofumigant fungus Muscodor albus (Ascomycota: Xylariales) for control of codling moth (Lepidoptera: Tortricidae) in simulated storage conditions. J. Econ. Entomol., 102, 43-49, doi. org/10.1603/029.102.0107

Lee S. et al., 2009. Mycofumigation with Oxyporus latemarginatus EF069 for control of postharvest apple decay and Rhizoctonia root rot on moth orchid. J. Appl. Microbiol., 106, 1213-1219, doi.org/10.1111/j.13652672.2008.04087.x

Lee S. et al., 2014. Arabidopsis thaliana for testing the phytotoxicity of volatile organic compounds. Plant Growth Regul., 74, 177-186, doi.org/10.1007/s10725014-9909-9

Lemfack M.C. et al., 2017. mVOC 2.0: a database of microbial volatiles. Nucleic Acids Res., 46, D1261-D1265, doi.org/10.1093/nar/gkx1016

Li Q. et al., 2015. Biofumigation on post-harvest diseases of fruits using a new volatile-producing fungus of Ceratocystis fimbriata. PLoS One, 10, e0132009, doi. org/10.1371/journal.pone.0132009

Lockwood J., 1977. Fungistasis in soils. Biol. Rev., 52, 1-43, doi.org/10.1111/j.1469-185x.1977.tb01344.x

Lockwood W. \& Langston Jr L., 1964. A reliable and easily sectioned epoxy embedding medium. Anat. Rec., 150 , 129-139, doi.org/10.1002/ar.1091500204

Malmierca M.G. et al., 2012. Involvement of Trichoderma trichothecenes in the biocontrol activity and in the induction of plant defense related genes. Appl. Environ. Microbiol., 78, 4856-4868, doi.org/10.1128/aem.0038512

Malmierca M.G. et al., 2015. Production of trichodiene by Trichoderma harzianum alters the perception of this biocontrol strain by plants and antagonized fungi. Environ. Microbiol., 17, 2628-2646, doi. org/10.1111/1462-2920.12506

McGuinness M. \& Dowling D., 2009. Plant-associated bacterial degradation of toxic organic compounds in soil. Int. J. Environ. Res. Public Health, 6, 2226-2247.

Mercier J. \& Jiménez J.I., 2004. Control of fungal decay of apples and peaches by the biofumigant fungus Muscodor albus. Postharvest Biol. Technol., 31, 1-8, doi.org/10.1016/j.postharvbio.2003.08.004

Mercier J. \& Smilanick J., 2005. Control of green mold and sour rot of stored lemon by biofumigation with Muscodor albus. Biol. Control, 32, 401-407, doi.org/10.1016/j. biocontrol.2004.12.002

Mercier J., Jiménez-Santamaría J.I. \& Tamez-Guerra P., 2007. Development of the volatile-producing fungus Muscodor albus Worapong, Strobel, and Hess as a novel antimicrobial biofumigant. Rev. Mex. Fitopatología, 25, 173-179.

Meshram V., Kapoor N. \& Saxena S., 2013. Muscodor kashayum sp. nov. - a new volatile anti-microbial producing endophytic fungus. Mycology, 4, 196-204, doi.org/10.1080/21501203.2013.877990

Minerdi D., Bossi S., Gullino M.L. \& Garibaldi A., 2009. Volatile organic compounds: a potential direct longdistance mechanism for antagonistic action of Fusarium oxysporum strain MSA 35. Environ. Microbiol., 11, 844854, doi.org/10.1111/j.1462-2920.2008.01805.x

Morath S.U., Hung R. \& Bennett J.W., 2012. Fungal volatile organic compounds: a review with emphasis on their biotechnological potential. Fungal Biol. Rev., 26, 73-83, doi.org/10.1016/j.fbr.2012.07.001

Morgenstern R.D., 2014. Economic analyses at EPA: assessing regulatory impact. New York, NY, USA: Routledge, doi.org/10.4324/9781315060682

Muller W.H., 1965. Volatile materials produced by Salvia leucophylla: effects on seedling growth and soil bacteria. Bot. Gazette, 126, 195-200, doi.org/10.1086/336319

Ogura T., $\quad$ Sunairi M. \& Nakajima M., 2000. 2-Methylisoborneol and geosmin, the main sources of soil odor, inhibit the germination of Brassicaceae seeds. Soil Sci. Plant Nutr., 46, 217-227.

Peñuelas J. et al., 2014. Biogenic volatile emissions from the soil. Plant Cell Environ., 37, 1866-1891, doi. org/10.1111/pce.12340

Polizzi V. et al., 2011. Autoregulatory properties of (+)-thujopsene and influence of environmental conditions on its production by Penicillium decumbens. Microb. Ecol., 62, 838-852, doi.org/10.1007/s00248011-9905-9

Quimby Jr P., Zidack N., Boyette C. \& Grey W., 1999. A simple method for stabilizing and granulating fungi. Biocontrol Sci. Technol., 9, 5-8, doi. org/10.1080/09583159929857

Reinhard J., Srinivasan M.V. \& Zhang S., 2004. Olfaction: scent-triggered navigation in honeybees. Nature, 427, 411, doi.org/10.1038/427411a

Romine M. \& Baker R., 1973. Soil fungistasis: evidence for an inhibitory factor. Phytopathology, 63, 756.

Saxena S., Meshram V. \& Kapoor N., 2014. Muscodor darjeelingensis, a new endophytic fungus of Cinnamomum camphora collected from northeastern Himalayas. Sydowia, 66, 55-67.

Schalchli H. et al., 2011. Antifungal activity of volatile metabolites emitted by mycelial cultures of saprophytic fungi. Chem. Ecol., 27, 503-513, doi.org/10.1080/02757 540.2011 .596832

Schüepp H. \& Frei E., 1969. Soil fungistasis with respect to pH and profile. Can. J. Microbiol., 15, 1273-1279, doi. org/10.1139/m69-231

Semighini C.P. et al., 2006. Farnesol-induced apoptosis in Aspergillus nidulans reveals a possible mechanism for antagonistic interactions between fungi.Mol.Microbiol., 59, 753-764, doi.org/10.1111/j.1365-2958.2005.04976.x

Siegel E. \& Wason S., 1986. Mothball toxicity. Pediatr. Clinics of North Am., 33, 369-374, doi.org/10.1016/ s0031-3955(16)35007-6 
Singh S.K. et al., 2011. An endophytic Phomopsis sp. possessing bioactivity and fuel potential with its volatile organic compounds. Microb. Ecol., 61, 729-739, doi. org/10.1007/s00248-011-9818-7

Stinson A., Zidack N., Strobel G. \& Jacobsen B., 2003 a. Mycofumigation with Muscodor albus and Muscodor roseus for control of seedling diseases of sugar beet and Verticillium wilt of eggplant. Plant Dis., 87, 1349-1354, doi.org/10.1094/pdis.2003.87.11.1349

Stinson M. et al., 2003b. An endophytic Gliocladium sp. of Eucryphia cordifolia producing selective volatile antimicrobial compounds. Plant Sci., 165, 913-922, doi. org/10.1016/s0168-9452(03)00299-1

Strobel G., Dirkse E., Sears J. \& Markworth C., 2001. Volatile antimicrobials from Muscodor albus, a novel endophytic fungus. Microbiology, 147, 2943-2950, doi. org/10.1099/00221287-147-11-2943

Strobel G. et al., 2008. Synergism among volatile organic compounds resulting in increased antibiosis in Oidium sp. FEMS Microbiol. Lett., 283, 140-145.

Strobel G., Manker D.C. \& Mercier J., 2010. Endophytic fungi and methods of use. Google Patents.

Strobel G. et al., 2011. An endophytic/pathogenic Phoma sp. from creosote bush producing biologically active volatile compounds having fuel potential. FEMS Microbiol. Lett., 320, 87-94, doi.org/10.1111/j.15746968.2011.02297.x

Suwannarach N. et al., 2013a. Molecular and morphological evidence support four new species in the genus Muscodor from northern Thailand. Ann. Microbiol., 63, 1341-1351, doi.org/10.1007/s13213-012-0593-6

Suwannarach N. et al., 2013b. Biofumigation with the endophytic fungus Nodulisporium spp. CMU-UPE34 to control postharvest decay of citrus fruit. Crop Prot., 45, 63-70, doi.org/10.1016/j.cropro.2012.11.015

Suwannarach N. et al., 2016. Evaluation of Muscodor suthepensis strain CMU-Cib462 as a postharvest biofumigant for tangerine fruit rot caused by Penicillium digitatum. J. Sci. Food Agric., 96, 339-345, doi. org/10.1002/jsfa.7099

Syed R.U.H. \& Geary B., 2013. An endophytic Nodulisporium sp. from Central America producing volatile organic compounds with both biological and fuel potential. J. Microbiol. Biotechnol., 23, 29-35, doi. org/10.4014/jmb.1208.04062
Thakore Y., 2006. The biopesticide market for global agricultural use. Ind. Biotechnol., 2, 194-208, doi. org/10.1089/ind .2006.2.194

Tomsheck A.R. et al., 2010. Hypoxylon sp., an endophyte of Persea indica, producing 1,8-cineole and other bioactive volatiles with fuel potential. Microb. Ecol., 60, 903-914, doi.org/10.1007/s00248-010-9759-6

USEPA Air Toxics Web Site. www.epa.gov/sites/production/ files/2016-09/documents/benzene.pdf, (March 13, 2020).

Watson A.G. \& Ford E.J., 1972. Soil fungistasis--a reappraisal. Annu. Rev. Phytopathol., 10, 327-346, doi. org/10.1146/annurev.py.10.090172.001551

Wheatley R., 2002. The consequences of volatile organic compound mediated bacterial and fungal interactions. Antonie Van Leeuwenhoek, 81, 357-364.

Worapong J. \& Strobel G.A., 2009. Biocontrol of a root rot of kale by Muscodor albus strain MFC2. BioControl, 54, 301-306, doi.org/10.1007/s10526-008-9175-8

Yu D. et al., 2015. Antifungal modes of action of tea tree oil and its two characteristic components against Botrytis cinerea. J. Appl. Microbiol., 119, 1253-1262, doi. org/10.1111/jam.12939

Zhang F., Yang X., Ran W. \& Shen Q., 2014a. Fusarium oxysporum induces the production of proteins and volatile organic compounds by Trichoderma harzianum T-E5. FEMS Microbiol. Lett., 359, 116-123, doi. org/10.1111/1574-6968.12582.

Zhang Q. et al., 2014b. Diversity and biocontrol potential of endophytic fungi in Brassica napus. Biol. Control, 72 , 98-108, doi.org/10.1016/j.biocontrol.2014.02.018

Zhang Q. et al., 2015. Production of anti-fungal volatiles by non-pathogenic Fusarium oxysporum and its efficacy in suppression of Verticillium wilt of cotton. Plant Soil, 392, 101-114, doi.org/10.1007/s11104-015-2448-y

Zhao J. et al., 2010. Antimicrobial metabolites from the endophytic fungus Pichia guilliermondii isolated from Paris polyphylla var. yunnanensis. Molecules, 15, 79617970, doi.org/10.3390/molecules 15117961

Zou C.-S. et al., 2007. Possible contributions of volatileproducing bacteria to soil fungistasis. Soil Biol.Biochem., 39, 2371-2379, doi.org/10.1016/j.soilbio.2007.04.009

(94 réf.) 